\title{
New PTEN mutation identified in a patient with rare bilateral choroidal ganglioneuroma
}

\author{
Zhaoxin Jiang ${ }^{\dagger}$, Ting Zhang ${ }^{\dagger}$, Chonglin Chen, Limei Sun, Songshan Li and Xiaoyan Ding ${ }^{*}$
}

\begin{abstract}
Background: Choroidal ganglioneuroma is an extremely rare tumor, and there is little knowledge regarding its pathogenesis. We aimed to investigate the phenotypic and genetic alterations in one sporadic patient with a rare case of bilateral choroidal ganglioneuroma.

Methods: A 6-year-old boy with histological diagnosis of bilateral ganglioneuroma was recruited for the study. Comprehensive ophthalmic examinations were performed. Genomic DNA was extracted from the peripheral blood samples collected from the patient, his unaffected family members, and 200 unrelated control subjects from the same population. Whole exome sequencing was performed and raw reads were aligned to the human genome reference (hg19) using Burrows-Wheeler Aligner. DNA from all available family members was Sanger sequenced for segregation analysis.

Results: Extensive bilateral retinal detachments were observed via optical coherence tomography. Diffuse thickening of choroid was identified with ultrasound B scan and magnetic resonance imaging. Genetic analysis revealed the presence of a novel heterozygous PTEN frameshift mutation, c.498delA (p.Thr167LeufsTer16), in exon 6. It was present in the affected individual, but not in any of the family members. Genetic analysis revealed that there was no mutation in neurofibromatosis-related genes in the family. Upon performing comprehensive systemic examinations, no obvious abnormalities in other organs were observed.

Conclusions: A novel de novo PTEN mutation was identified in a patient with bilateral choroidal ganglioneuroma. Although PTEN mutations are known to induce multiple abnormalities, choroidal ganglioneuroma can be the first manifestation without abnormalities in other organs. Further studies are needed to confirm the association between choroidal ganglioneuroma and PTEN mutation.
\end{abstract}

Keywords: Choroidal ganglioneuroma, PTEN mutation, Whole exome sequencing

\footnotetext{
* Correspondence: dingxiaoyan@gzzoc.com

${ }^{\dagger}$ Zhaoxin Jiang and Ting Zhang contributed equally to this work.

State Key Laboratory of Ophthalmology, Zhongshan Ophthalmic Center, Sun

Yat-sen University, Guangzhou 510060, China
}

(c) The Author(s). 2020 Open Access This article is licensed under a Creative Commons Attribution 4.0 International License, which permits use, sharing, adaptation, distribution and reproduction in any medium or format, as long as you give appropriate credit to the original author(s) and the source, provide a link to the Creative Commons licence, and indicate if changes were made. The images or other third party material in this article are included in the article's Creative Commons licence, unless indicated otherwise in a credit line to the material. If material is not included in the article's Creative Commons licence and your intended use is not permitted by statutory regulation or exceeds the permitted use, you will need to obtain permission directly from the copyright holder. To view a copy of this licence, visit http://creativecommons.org/licenses/by/4.0/. The Creative Commons Public Domain Dedication waiver (http://creativecommons.org/publicdomain/zero/1.0/) applies to the data made available in this article, unless otherwise stated in a credit line to the data. 


\section{Background}

Choroidal ganglioneuroma is an extremely rare disease, with only 13 reported cases [1-13]. Ganglioneuroma is a benign neurogenic tumor with an incidence of approximately 1 case per million children in the United States $[14,15]$. It arises from the neural crest [16], and is considered as a subset of neuroblastomas that histopathologically consist of mature ganglion-like cells with scarce immature cells $[17,18]$. The underlying mechanism of the development of ganglioneuroma is still unclear.

According to the previous reports, blindness and painful eyes were common features, and 12 out of 13 cases had neurofibromatosis type 1 (NF-1), which suggests that choroidal ganglioneuromas could be a rare manifestation within the clinicopathologic spectrum of NF-1 syndrome [19]. Recently, we encountered the first case of bilateral choroidal ganglioneuromas, and reported the multimodal imaging features in the early stage [20].

With the aim to unravel the pathogenesis of this rare disease, whole exome sequencing was carried out, and a novel phosphatase and tensin homolog (PTEN) mutation was identified in the patient. The results suggest that there may be an association between choroidal ganglioneuroma and the PTEN mutation.

\section{Methods}

\section{Study participants}

This study was performed as per the guidelines approved by the Ethics Committee of Zhongshan Ophthalmic Center (ZOC), Sun Yat-sen University and in accordance with the Declaration of Helsinki. Written informed consent was obtained from all subjects.

A 6-year-old boy complaining of gradual bilateral vision loss for the last 2 years presented in Pediatric Ophthalmology Department, ZOC. Comprehensive ophthalmic examinations were performed, including visual acuity, intraocular pressure (IOP), slit lamp microscopy, fundus photography (Heidelberg Engineering, Inc., Heidelberg, Germany), optical coherence tomography (OCT; Carl Zeiss Meditec, Inc., Dublin, CA, USA), ultrasound B scan (Aitomu Machinery Co. Ltd., Shanghai, China), and magnetic resonance imaging (MRI; General Electric, Milwaukee, WI). As choroidal ganglioneuroma was diagnosed based on previous choroidal biopsy, extensive examinations were performed to screen any systemic involvement. Whole exome sequencing was performed to unravel the genetic pathogenesis of this rare disease.

\section{DNA sample collection}

The proband was the second child of healthy parents (Fig. 1). The parents had no knowledge of any cancer, or diseases associated with NF and PTEN hamartoma tumor syndrome. Blood samples were collected from the

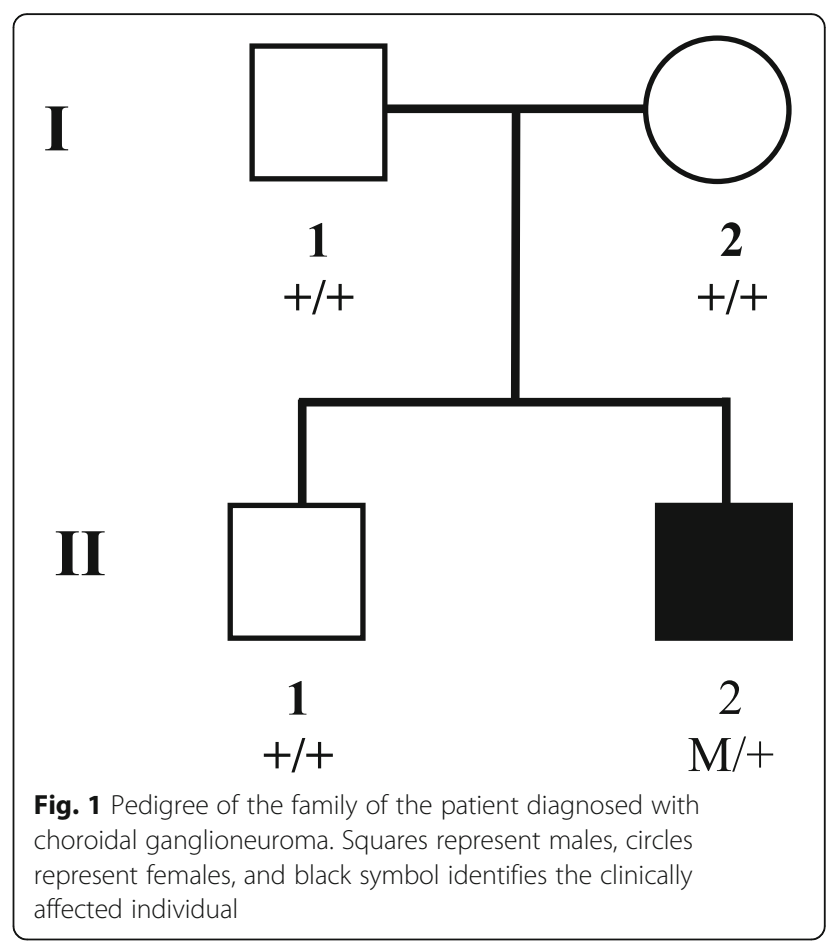

proband and his unaffected family members. A total of 200 individuals from the same population, who exhibited no diagnostic features of tumor, neurofibromatosis or PTEN hamartoma tumor syndrome, were recruited to serve as normal control population $(41.99 \pm 15.62$ years old, 105 males/95 females). Genomic DNA was extracted using the TIANamp Blood DNA Kit (Tiangen Biotech, Beijing, China) according to the manufacturer's instructions. The quantity and quality of DNA were verified with NanoDrop (2000c Model, Thermo Fisher, US).

\section{Library preparation and targeted sequencing}

Illumina paired-end libraries were prepared using the Kapa LTP library prep kit (Roche, Basel, Switzerland) according to the manufacturer's protocol. Briefly, genomic DNA was sheared into fragments approximately 300$500 \mathrm{bp}$ in length. The DNA fragments were end-repaired and an extra 'adenine' base was added to the 3 ' end. Illumina adapters were ligated to the ends of the DNA fragments and subsequently four cycles of PCR amplification were performed on each sample. The DNA libraries were quantified using Qubit 3.0. Pre-capture libraries were pooled together for each capture reaction. Agilent SSELXT Human All Exon V6 was used for whole exome sequencing (Agilent, Santa Clara, CA, USA). The enriched DNA library was sequenced on Illumina Xten Analyzers, at 150 cycles per read, to generate paired-end reads following the manufacturer's standard sequencing protocols. 


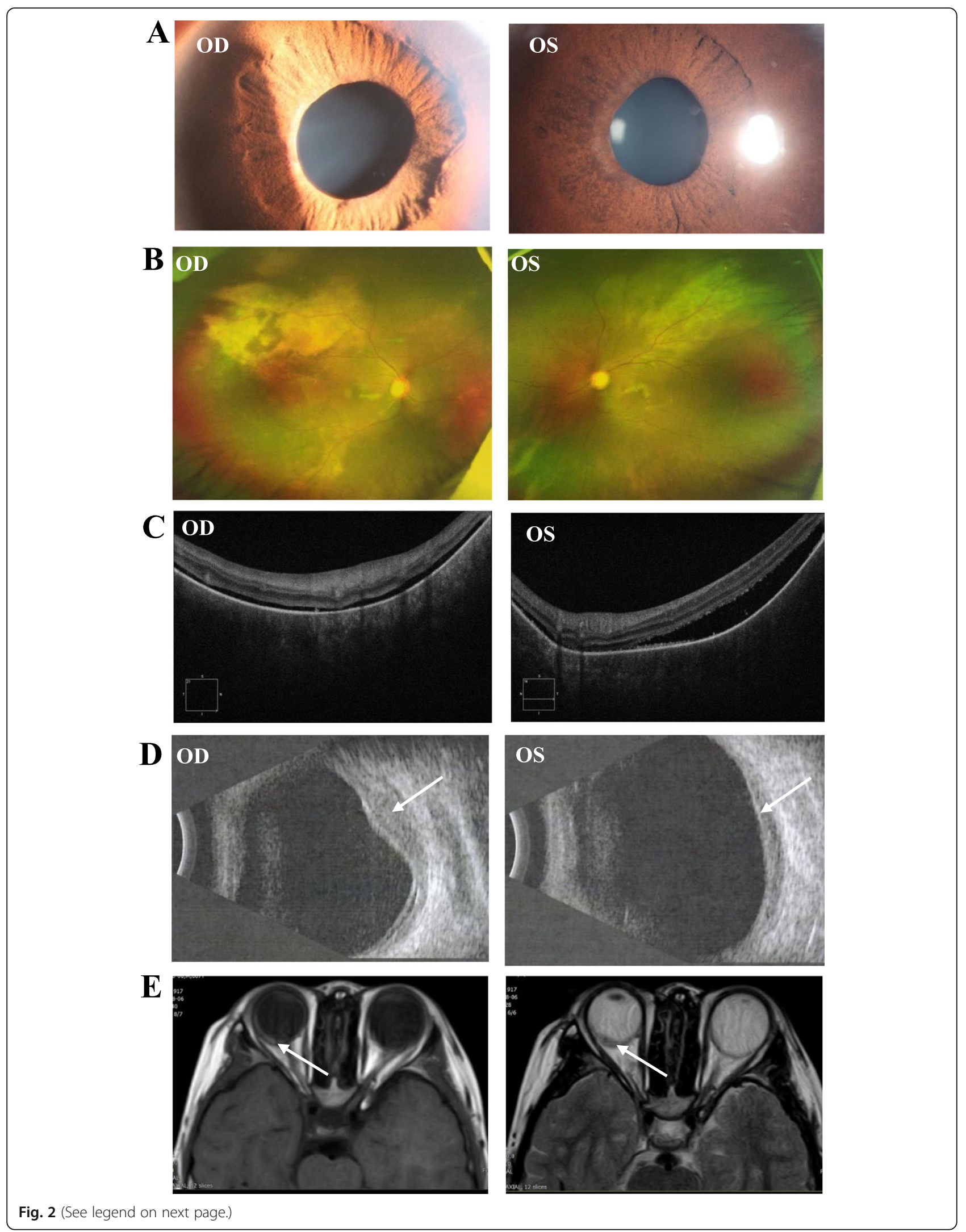


(See figure on previous page.)

Fig. 2 Images of comprehensive ophthalmic examinations. a The bilateral pupils were irregular and unable to dilate. b Funduscopy showed vasculitis and exudation bilaterally. c Bilateral retinal detachment was observed in optical coherence tomography. Choroidal vasculature was dramatically absent. $\mathbf{d}$ A dome-shaped mass bulging from choroid to retina was observed in B scan. e Diffuse thickening of bilateral choroids was verified with magnetic resonance imaging

\section{Bioinformatic analysis of sequencing results}

Raw reads were aligned to the human genome reference (hg19) using the Burrows-Wheeler Aligner. Singlenucleotide variants (SNVs) and insertions and deletions (InDels) were called by GATK4.0 HC. The frequency of all SNVs and InDels was annotated using the ExAC, gnomAD, HGVD, CHARGE, 1000 Genome, UK10K databases, and the internal database of Clinbytes Inc. to filter the common variants, with an allele frequency cutoff of 0.5 and $0.1 \%$ for recessive and dominant variants, respectively.

\section{Genetic validation}

After the confirmation of pathological variants in the proband, samples from all available and consenting family members were Sanger sequenced for segregation analysis. PCR primer sets were designed via Primer3 and products were sequenced on an ABI 3700XL Genetic Analyzer. The sequences of forward and reverse primers used for amplification of PTEN are 5'-GGCTACGACC CAGTTACCATAG-3' and 5' '-TGGGACAGGTTCTT CCATCATC-3', respectively.

\section{Results}

\section{Ocular findings}

In an initial examination of the proband 2 years ago, the best corrected visual acuity was $20 / 50$ in the right eye and $20 / 32$ in the left. In a more recent visit, it was hand motion/10 cm and 20/200, respectively. The IOP had fluctuated around the normal range in the past, but 40 $\mathrm{mmHg}$ IOP was observed in recent visit, and was controlled by administering brinzolamide-timolol eyedrops.

Bilateral and extensive retinal detachments were observed in OCT. Diffuse thickening of choroid was identified via B scan and MRI (Fig. 2). There was a high probability of occurrence of a choroidal tumor, and a choroid biopsy confirmed the histological diagnosis of choroidal ganglioneuroma. More details on the multimodal images can be found in our previous report [20].

\section{Mutation screening}

Genetic analysis documented the presence of a heterozygous PTEN frameshift mutation, c.498delA (p.Thr167LeufsTer16), in exon 6 (NM_000314) in the affected individual, but not in any of the unaffected family members. Therefore, this was considered as a de novo mutation. The identified mutation has not been reported previously and was not observed in any of the 200 unrelated control individuals from the same population (Fig. 3). The c.498delA variant causes a frameshift mutation starting with codon threonine-167, changing this amino acid to a leucine residue, and creates a premature stop codon at position 16 of the new reading frame, denoted as p.Thr167LeufsTer16. It is predicted that this variant can

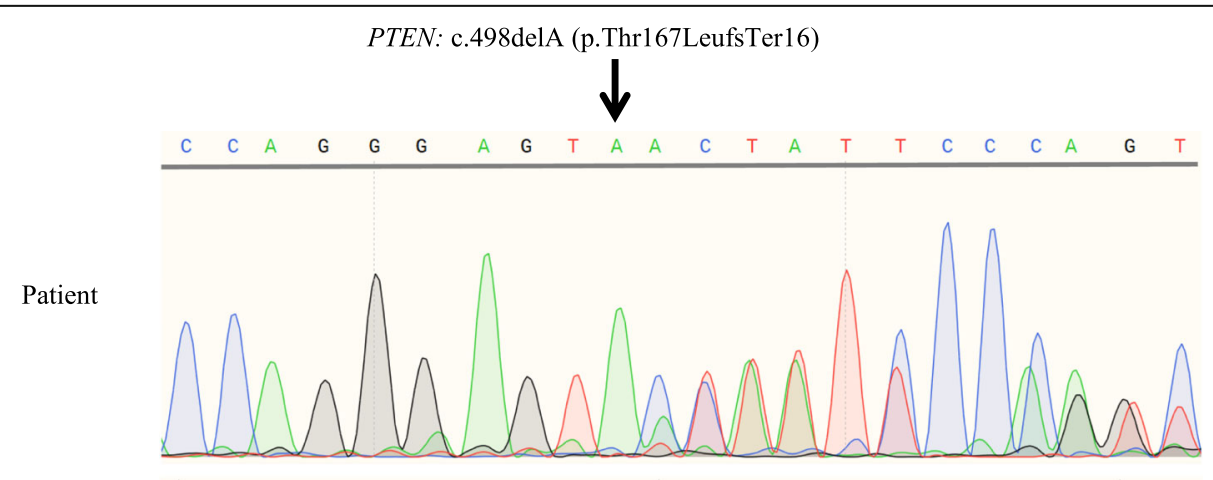

Normal

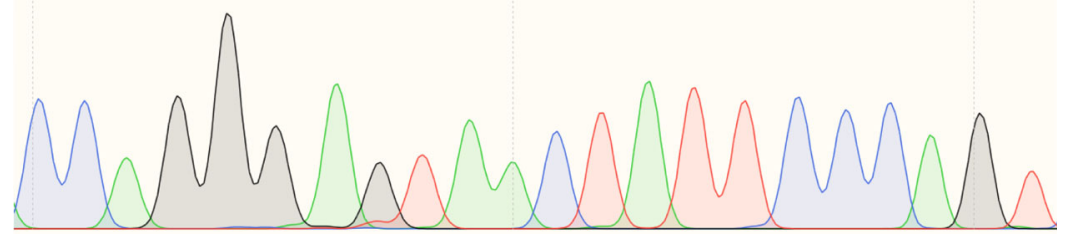

Fig. 3 DNA sequence of a region of the PTEN gene in the patient and unaffected individuals. A heterozygous PTEN frameshift mutation c.498delA (p.Thr167LeufsTer16) in exon 6 (NM_000314) was identified in the affected individual, but not in the unaffected family members or unrelated control subjects 
Table 1 Clinical profiles of choroidal ganglioneuroma cases in literature

\begin{tabular}{|c|c|c|c|c|c|c|c|}
\hline & Case & Sex & Age (Years) & Eye & Clinical presentation & NF-1 & Treatment \\
\hline 1 & Wolter & Female & 42 & Left & Cataract, glaucoma, buphthalmos & Yes & Enucleation \\
\hline 2 & Woog et al & Female & 21 & Left & Cataract, retinal detachment, buphthalmos & Yes & Enucleation \\
\hline 3 & Browstein et al & Female & $<1$ & Left & $\begin{array}{l}\text { Congenital glaucoma, buphthalmos, plexiform } \\
\text { neurofibroma }\end{array}$ & Yes & Enucleation \\
\hline 4 & Shome et al & Male & 11 & Left & $\begin{array}{l}\text { Glaucoma, buphthalmos, plexiform neurofibroma, } \\
\text { sphenoid wing dysplasia }\end{array}$ & Yes & Evisceration \\
\hline 5 & Ishijima et al & Male & 7 & Left & Cataract, retinal detachment, buphthalmos & Yes & Enucleation \\
\hline 6 & Lad et al & Female & $<1$ & Right & Cataract, buphthalmos, sphenoid wing dysplasia & Yes & Enucleation \\
\hline 7 & Yazici et al & Female & 17 & Left & $\begin{array}{l}\text { Cataract, glaucoma, buphthalmos plexiform } \\
\text { neurofibroma }\end{array}$ & Yes & Evisceration \\
\hline 8 & Goyal et al & Female & $<1$ & Right & Buphthamos, hypoglobus, plexiform neurofibroma & Yes & $\begin{array}{l}\text { Exenteration via } \\
\text { craniotomy access. }\end{array}$ \\
\hline 9 & Chang et al & Male & 42 & Right & Cataract, optic nerve glioma, neurofibroma, & Yes & Enucleation \\
\hline 10 & Mbagwu et al & Female & 5 & Right & Proptosis, glaucoma, sphenoid wing dysplasia & Yes & Enucleation \\
\hline 11 & Abdulkader et al & Male & 50 & Right & $\begin{array}{l}\text { Cataract, glaucoma, buphthalmos, plexiform } \\
\text { neurofibroma, frontoethmoidal encephalocele }\end{array}$ & Yes & Orbital exenteration \\
\hline 12 & DeParis et al & Female & 5 & Right & $\begin{array}{l}\text { Glaucoma, retinal detachment, macrocephaly, } \\
\text { developmental delay }\end{array}$ & No & Enucleation \\
\hline 13 & Gilani et al & Male & 7 & Not mentioned & $\begin{array}{l}\text { Invading plexiform neurofibroma, choroidal } \\
\text { layer expanding }\end{array}$ & Yes & Enucleation \\
\hline 14 & Present case & Male & 6 & Bilateral & $\begin{array}{l}\text { Retinal detachment and diffuse choroidal } \\
\text { thickening }\end{array}$ & No & IOP lowering medicines \\
\hline
\end{tabular}

cause loss of normal protein function either through protein truncation or nonsense-mediated mRNA decay.

As most reported cases of choroidal ganglioneuroma showed a medical history of NF-1, genetic changes in neurofibromatosis-related genes were evaluated for all subjects. Genetic analysis showed that there was no mutation in NF1- or NF2-related genes in the proband and his unaffected family members. There was no pathogenic or a potential pathogenic mutation in NF-related genes in any of the 200 unrelated controls.

\section{Systemic workup}

Since the patient had choroidal ganglioneuroma and the mutation in PTEN, it was crucial to rule out the presence of other ganglioneuromas, or PTEN related abnormalities in other tissues. The patient was subjected to comprehensive systemic examinations, including general physical examination, ultrasound scan of the thyroid gland, liver and kidney, CT scan of the mediastinum and retroperitoneum, and no obvious abnormalities were detected.

\section{Discussion}

According to the reported studies (Table 1), most cases of choroidal ganglioneuroma shared some common features. First, most cases of uveal ganglioneuroma co-occurred with NF-1, leading to the diagnosis as NF-1with orbitfacial involvement [19]. Second, ganglioneuroma led to unilateral blindness and pain in the eye and ended up with evisceration/enucleation in all cases. Third, ganglioneuromas were diagnosed unexpectedly only after subsequent histopathological examination. Genetic examination performed in one of the cases diagnosed as Cowden syndrome revealed a mutation in PTEN gene.

In this case, retinal detachment was a major early manifestation, and choroidal tumor was suspected when the thickness of the choroid increased. There were no clinical features that supported NF-1 throughout extensive examinations. Choroidal biopsy was performed and the diagnosis of ganglioneuroma was confirmed [20]. Interestingly, this is the first case of bilateral choroidal ganglioneuroma. Thus, whole exome sequencing was performed and a de novo PTEN mutation was identified. PTEN is a tumor suppressor gene that classically dampens the PI3K/AKT/ mTOR growth-promoting signaling cascade [21]. Loss of PTEN function results in increased cell proliferation, survival, and tumorigenesis [22, 23], manifesting as diverse human pathologies, and leading to the use of the umbrella term, PTEN hamartoma tumor syndrome (PHTS) [24, 25]. Thus, based on histologic features, this case was diagnosed as choroidal ganglioneuroma. Besides, based on genetic findings, this case was diagnosed as PHTS manifesting with choroidal ganglioneuroma.

The association among PTEN, GN, and NF is not clearly known yet, but studies have shown some common underlying pathogenic mechanisms. NF-1 is considered to be a syndrome that increases disposition to 
tumors, since individuals with NF-1 are 10 to 50 times more prone to a diverse spectrum of benign and malignant tumors than the general population [26, 27]. On the other hand, several reports support that there are alterations of PTEN-controlled signaling pathways in NF [28]. For instance, NF associated high-grade glioma models have been established by coupling complete inactivation of NF-1 and PTEN genes [29, 30]. Also, several studies have demonstrated a role of neurofibromin, the protein product of $N F-1$, in controlling mammalian target of rapamycin (mTOR) signaling, which indicates the involvement of PTEN-related PI3K/AKT/mTOR pathway in the etiology of NF-1 [31, 32].

In the current case, it is interesting that there are no features of NF or PHTS. We speculate that this can be due to no pathogenic mutation in NF-related genes and the young age of the patient. Different cancer risks have been reported in PHTS and age is an important variable. For instance, Tan et al. studied 368 individuals with PTEN mutation and showed that risks of developing colorectal and kidney cancers began around the age of 40 , with a lifetime risk of 9 and 34\% respectively [33]. The penetrance of breast cancer is particularly elevated, beginning around the age of 30 and rising to an estimated $85 \%$ lifetime risk in females [33]. Nieuwenhuis et al. analyzed the data from 180 patients with PTEN mutations and reported that cumulative risk of developing any cancer was $9 \%$ at the age of 30 , but it increased to $55.7 \%$ at the age of 60 in males [34]. Thus, genetic study is important for the diagnosis, as PTEN mutations are known to increase risks for multiple common cancers. Lifetime cancer risk estimates and close follow-ups are highly recommended for the proband in the present case.

One limitation of the present study is the limited case number. Choroidal ganglioneuroma is an extremely rare disease and most reported cases are not diagnosed until evisceration/enucleation. Therefore, it might be very difficult to recruit enough cases for a case-series study. Furthermore, biopsy and genetic testing are critical for the early and accurate diagnosis of choroidal ganglioneuroma.

\section{Conclusion}

A novel de novo PTEN mutation was identified in a bilateral choroidal ganglioneuroma patient. Although PTEN mutation has been considered to induce multiple abnormalities, choroidal ganglioneuroma can be the first clinic manifestation without abnormalities in other organs. Further studies are needed to confirm this new association between choroidal ganglioneuroma and the PTEN mutation.

\section{Acknowledgements}

We would like to thank Dr. Chi-chao Chan from National Eye Institute, USA, for her professional opinion in the pathological diagnosis, Prof. Xiaoyan Peng from Beijing Tongren Hospital, China, for her great help in imaging analysis.

\section{Authors' contributions}

XD conceived and designed the study, and critically reviewed the manuscript. ZJ, TZ, LC and SL participated in data collection, laboratory analysis and interpretation. ZJ and LS analyzed the data and wrote the first draft of the manuscript. All authors approved the submitted version.

\section{Funding}

This study was supported in part by grants from the Fundamental Research Funds of State Key Laboratory of Ophthalmology, research funds of Sun Yatsen University (15ykjc22d; Guangzhou, Guangdong, China), Science and Technology Program Guangzhou, China (201803010031; Guangzhou, Guangdong, China), and China Postdoctoral Science Foundation (no.2019 M663257). The sponsors and funding organizations had no role in the design or conduct of this research.

\section{Availability of data and materials}

All the data used to support the findings of this study are included within the article and are available from corresponding author by a reasonable request.

\section{Ethics approval and consent to participate}

All procedures adhered to the tenets of the Declaration of Helsinki, and local approval was received from the Investigational Review Board of Zhongshan Ophthalmic Center, Sun Yat-sen University.

Written informed consent for participation in the study was obtained where participants are children (under 16 years old) from their parent or guardian.

\section{Consent for publication}

Written informed consent for the publication of these details have been obtained from the patient's parents. Written consent for publication was obtained from all family members who provided DNA samples.

\section{Competing interests}

The authors declare that they have no competing interests.

Received: 2 June 2020 Accepted: 7 December 2020

Published online: 11 December 2020

\section{References}

1. Wolter JR, Bryson JM, McKee TP. Ganglioneuromelanocytosis of the choroid with bilateral juvenile Glaucoma. Arch Ophthalmol. 1965;74:353-6.

2. Woog JJ, Albert DM, Craft J, Silberman N, Horns D. Choroidal ganglioneuroma in neurofibromatosis. Graefes Arch Clin Exp Ophthalmol. 1983;220:25-31.

3. Brownstein S, Little JM. Ocular neurofibromatosis. Ophthalmology. 1983;90: 1595-9.

4. Shome D, Vemuganti GK, Honavar SG. Choroidal ganglioneuroma in a patient with neurofibromatosis type 1: a case report. Eye (Lond). 2006;20: 1450-1.

5. Ishijima K, Kase S, Noda M, Ishida S. Intraocular neovascularization associated with choroidal ganglioneuroma in neurofibromatosis type 1. Eur J Ophthalmol. 2011;21:837-40.

6. Lad EM, Karamchandani JR, Alcorn DM, Moshfeghi DM, Egbert PR. Retinal glioneuronal hamartoma in neurofibromatosis type 1. Arch Ophthalmol. 2012:130:1335-7.

7. Yazici B, Ozgun G, Adim SB. Choroidal ganglioneuroma in a patient with orbitopalpebral neurofibromatosis. Ophthalmic Plast Reconstr Surg. 2014;30: e140-2.

8. Goyal S, Park A, Zeglam A, Brown H, Pemberton JD. Choroidal Ganglioneuroma and orbital Plexiform Neurofibroma presenting as Buphthalmos in an infant with Neurofibromatosis type 1. Ophthalmic Plast Reconstr Surg. 2016;32:e87-9.

9. Chang I, Juric-Sekhar G, Marshall D, Zhang J. An incidental finding of Choroidal Ganglioneuronal Hamartoma in a patient with Neurofibromatosis type 1. Ophthalmic Plast Reconstr Surg. 2017;33:S40-2.

10. Mbagwu M, Rahmani B, Srivastava A, Burrowes D, Bryar PJ. Unsuspected Ganglioneuroma of the choroid diagnosed after Enucleation. Ocul Oncol Pathol. 2015;2:48-50

11. Abdulkader MM, Dalesandro MF, Mendenhall SK, Shah MV, Bonnin JM. Ciliochoroidal ganglioneuroma in neurofibromatosis type 1: report of a case and review of the literature. Neuropathology. 2016;36:464-9. 
12. DeParis SW, Bloomer M, Han Y, et al. Uveal Ganglioneuroma due to Germline PTEN mutation (Cowden syndrome) presenting as unilateral infantile Glaucoma. Ocul Oncol Pathol. 2017;3:122-8.

13. Gilani A, Treece A. Choroidal Ganglioneuronal Hamartoma in Neurofibromatosis Type-1. J Pediatr Ophthalmol Strabismus. 2018;55:412.

14. De Bernardi B, Gambini C, Haupt R, et al. Retrospective study of childhood ganglioneuroma. J Clin Oncol. 2008;26:1710-6.

15. Geoerger B, Hero B, Harms D, Grebe J, Scheidhauer K, Berthold F. Metabolic activity and clinical features of primary ganglioneuromas. Cancer. 2001;91: 1905-13.

16. Dai X, Zhang R, Li Y, Wu G. Multiple ganglioneuromas: a report of a case and review of the ganglioneuromas. Clin Neuropathol. 2009;28:193-6.

17. Lonergan GJ, Schwab CM, Suarez ES, Carlson CL. Neuroblastoma, ganglioneuroblastoma, and ganglioneuroma: radiologic-pathologic correlation. Radiographics. 2002;22:911-34

18. Wu W, Xu WJ, Liu JB, Sun J, Huang YM, Lv ZB. Exome sequencing identifies predisposing and fusion gene in ganglioneuroma, ganglioneuroblastoma and neuroblastoma. Math Biosci Eng. 2019;16:7217-29.

19. Ozgun G, Adim SB, Ugras N, Yazici B. Co-occurrence of choroidal pigmented ganglioneuroma and plexiform neurofibroma in a patient with neurofibromatosis 1. Kaohsiung J Med Sci. 2014;30:215-6.

20. Jiang ZZT, Xiu X, Liang D, Zhong Y, Chan C, Ding X. Multimodal Imaging Features of Bilateral Choroidal Ganglioneuroma. J Ophthalmol. 2020;2020: 6231269 Accepted.

21. Yehia L, Keel E, Eng C. The Clinical Spectrum of PTEN Mutations. Annu Rev Med. 2020;71:103-16.

22. Chalhoub N, Baker SJ. PTEN and the PI3-kinase pathway in cancer. Annu Rev Pathol. 2009:4:127-50.

23. Wang Y, Liu Y, Du Y, Yin W, Lu J. The predictive role of phosphatase and tensin homolog (PTEN) loss, phosphoinositol-3 (PI3) kinase (PIK3CA) mutation, and PI3K pathway activation in sensitivity to trastuzumab in HER2-positive breast cancer: a meta-analysis. Curr Med Res Opin. 2013;29: 633-42.

24. Mester J, Charis E. PTEN hamartoma tumor syndrome. Handb Clin Neurol. 2015:132:129-37.

25. Ngeow J, Eng C. Germline PTEN Mutation analysis for PTEN Hamartoma tumor syndrome. Methods Mol Biol. 2016;1388:63-73.

26. Campian J, Gutmann DH. CNS tumors in Neurofibromatosis. J Clin Oncol. 2017:35:2378-85.

27. Gutmann DH, Rasmussen SA, Wolkenstein P, et al. Gliomas presenting after age 10 in individuals with neurofibromatosis type 1 (NF1). Neurology. 2002; 59:759-61.

28. Gregorian C, Nakashima J, Dry SM, et al. PTEN dosage is essential for neurofibroma development and malignant transformation. Proc Natl Acad Sci U S A. 2009;106:19479-84.

29. Kwon $\mathrm{CH}$, Zhao D, Chen J, et al. Pten haploinsufficiency accelerates formation of high-grade astrocytomas. Cancer Res. 2008;68:3286-94.

30. Zuckermann M, Hovestadt V, Knobbe-Thomsen CB, et al. Somatic CRISPR/ Cas9-mediated tumour suppressor disruption enables versatile brain tumour modelling. Nat Commun. 2015;6:7391.

31. Dasgupta B, Yi Y, Chen DY, Weber JD, Gutmann DH. Proteomic analysis reveals hyperactivation of the mammalian target of rapamycin pathway in neurofibromatosis 1-associated human and mouse brain tumors. Cancer Res. 2005;65:2755-60.

32. Johannessen CM, Reczek EE, James MF, Brems H, Legius E, Cichowski K. The NF1 tumor suppressor critically regulates TSC2 and mTOR. Proc Natl Acad Sci U S A. 2005;102:8573-8.

33. Tan MH, Mester JL, Ngeow J, Rybicki LA, Orloff MS, Eng C. Lifetime cancer risks in individuals with germline PTEN mutations. Clin Cancer Res. 2012;18: 400-7.

34. Nieuwenhuis MH, Kets CM, Murphy-Ryan M, et al. Cancer risk and genotypephenotype correlations in PTEN hamartoma tumor syndrome. Familial Cancer. 2014;13:57-63.

\section{Publisher's Note}

Springer Nature remains neutral with regard to jurisdictional claims in published maps and institutional affiliations.

Ready to submit your research? Choose BMC and benefit from:

- fast, convenient online submission

- thorough peer review by experienced researchers in your field

- rapid publication on acceptance

- support for research data, including large and complex data types

- gold Open Access which fosters wider collaboration and increased citations

- maximum visibility for your research: over $100 \mathrm{M}$ website views per year

At BMC, research is always in progress.

Learn more biomedcentral.com/submissions 